\title{
Revista

\section{As receitas para o corpo belo e saudável encontradas nas páginas de Time e Veja}

\author{
The recipes for the health and beautiful body found on Time's and Veja's pages \\ VÂNIA DE VASCONCELOS GICO \\ Professora do Programa de Pós-Graduação em Ciências Sociais da Universidade Federal do Rio Grande do Norte - UFRN. \\ <vaniagico@gmail.com> \\ LIA HECKER LUZ \\ Doutoranda em Ciências Sociais pela Universidade Federal do Rio Grande do Norte - UFRN. \\ $<$ liahluz@gmail.com>
}

\section{RESUMO}

Análise de matérias sobre a busca do corpo belo e saudável publicadas nas edições de janeiro a junho de 2005 das revistas Veja e Time, com o objetivo de identificar os padrões de beleza e saúde reforçados pelo discurso midiático e apresentar reflexões sobre o estatuto do corpo na sociedade moderna. Time aborda o problema motivada por uma polêmica que está em pauta na sociedade norte-americana, sem apresentar dietas ou exercícios da moda ou o corpo magro e belo como o único saudável. Já Veja embarca nas ondas do consumo da beleza, ao trazer duas matérias de dietas da moda, cultuando mais a busca pelo corpo magro e dentro dos padrões estéticos do que pelo necessariamente saudável.

Palavras-chave: Revista Semanal; Magreza; Corpo Saudável.

\begin{abstract}
Analysis of news stories on the search for the beautiful and healthy body published on Veja's and Time's editions from January to June 2005, with the goal to identify the beauty and health standards reinforced by the media discourse and to present reflections about the body statute in modern society. Time approaches the problem motivated by a polemic in the agenda of North-American society, without presenting fashion diets or exercises neither the slim body as the only healthy possible one. Veja, on the other hand, embarks on the waves of beauty consumption by bringing two news stories on fashion diets, worshiping the search for the slim and within the esthetics standard body as opposed to the healthy one.

KeYwords: Weekly Magazine; Slimness; Healthy Body.
\end{abstract}




\section{corpo na sociedade moderna}

Embora, muitas vezes, reduzida ao seu aspecto meramente biológico, a doença resulta de um conjunto de significados e sentidos, traduzidos no nível simbólico como discurso e/ou sintoma, não podendo ser isolada de nossa condição de seres socializados, situados no universo sociocultural. Conforme asseverou Freyre (2009), é preciso enxergar o indivíduo como um homem situado como um todo biossociocultural. Ou seja, um todo biológico, ecológico e socioculturalmente condicionado, que depende de determinadas situações e não apenas daquela herança biológica que o predispõe a tais ou quais condições de saúde ou enfermidade. “O sociólogo da medicina não se ocupa do homem apenas como indivíduo, como unidade biofísica, mas do indivíduo socializado em pessoa" (Freyre, 2009, p. 63).

Segundo o autor, todo indivíduo sofre a influência do tipo de civilização a que pertence, sendo, dessa forma, necessário considerar o ser humano sempre a partir de três dimensões, a física (no caso, biológica), a social e a cultural, integrando os saberes biológicos e sociológicos. De cada uma dessas dimensões pode vir o fator precipitante da doença, sem que os demais sejam menosprezados, visto que, os fatores socioculturais, por exemplo, aparecem, em várias doenças, ora como fatores precipitantes, ora apenas como contribuintes.

Muitas vezes, doenças aparentemente orgânicas nada mais são do que expressões de reação de indivíduos biossocialmente mal ajustados a normas demasiadamente rígidas de convivência socioculturalmente condicionada, conforme ocorre na atualidade com as vítimas do bullying, caracterizado por atos de violência, física ou psicológica, intencionais e repetidos ou com muitas pessoas que, não aceitando o próprio corpo, mergulham numa busca desenfreada pela perda de peso com vias a se encaixarem nos padrões estéticos hegemônicos, desenvolvendo, muitas vezes, distúrbios alimentares, como a anorexia, a bulimia e a compulsão por alimentos. 
Conforme defendem Adam e Herzlich (2001), a interpretação coletiva da doença, ou de padrões estéticos socialmente aceitos, efetua-se sempre em termos que envolvem a sociedade, suas regras e a visão que dela temos, de forma que a concepção que temos de doença manifesta nossa relação com a ordem social. "Para interpretar os fenômenos orgânicos, as pessoas apoiam-se em conceitos, símbolos e estruturas de referências interiorizadas conforme os grupos sociais e culturais a que pertencem" (Adam; Herzlich, 2001, p. 82).

A partir dessa ideia de que tanto a doença como os padrões estéticos são construções biossocioculturais, modulados segundo diferentes grupos sociais e culturais, questionamos, a partir da análise de matérias jornalísticas relativas a dietas e busca do peso ideal publicadas nas revistas semanais Veja e Time, quais seriam alguns desses referenciais interiorizados na sociedade atual em relação à obesidade, à magreza e ao corpo saudável. Para responder tal questão, precisamos, antes, debater os principais conceitos que caracterizam nossa sociedade, o que faremos com base no pensamento de Anthony Giddens.

Segundo esse autor (1991; 1994; 2000), a sociedade moderna, ou modernidade, refere-se ao estilo, ao costume de vida e à organização social que emergiram na Europa a partir do século XVII e que acabaram se tornando mais ou menos mundiais em sua influência e nos desvencilharam de todos os tipos tradicionais de ordem social. Tal sociedade pode ser descrita, ainda, como aquela que superou seu passado, não estando mais sujeita às tradições, aos costumes, aos hábitos, às rotinas, às expectativas e às crenças que caracterizavam sua história. O mundo hoje seria um mundo pós-tradicional, no qual inúmeras tradições, crenças e costumes se misturam entre si. Nesse novo cenário, temos um passado cada vez mais enfraquecido, e, consequentemente, mais olhares voltados para o futuro, conforme nos assegura Giddens: 
Quando o passado perde sua influência, ou torna-se apenas uma "razão", entre outras, para alguém fazer o que faz, os hábitos preexistentes representam apenas diretrizes limitadas para a ação; ao passo que o futuro, aberto a numerosos "cenários", torna-se irresistivelmente interessante."

(1994, p. 92)

Esse novo paradigma acaba por operar alterações no nível identitário dos indivíduos. Se, enquanto nos tempos pré-modernos nossa relação com a sociedade, nossa identidade social era restringida e limitada pela tradição, pelo parentesco e pela localidade, hoje essa relação é muito mais ambígua. O indivíduo agora é o responsável pela sua própria identidade social, e não mais os contextos, as comunidades e as expectativas que antes delimitavam a noção de quem era e como vivia.

Assim, sustenta Giddens, como a tradição e os costumes não garantem mais quem somos nós, o reconhecimento da própria identidade através das relações pessoais e sociais torna-se regra básica da vida moderna. Ao lado dessa autopercepção, continua o autor, também é necessário empreender um projeto reflexivo individual, buscando um caminho próprio entre as ameaças e promessas da sociedade moderna.

Dessa forma, estaríamos vivendo o que o autor define como a reflexividade social, a qual diz respeito a "uma sociedade onde as condições em que vivemos são cada vez mais resultado de nossas próprias ações, e, inversamente, nossas ações visam cada vez mais a administrar ou enfrentar os riscos e oportunidades que nós mesmos criamos" (Giddens; Pierson, 2000, p. 20). Em outras palavras, a reflexividade da vida social moderna consistiria no fato de que nossas práticas sociais são 
constantemente examinadas e reformadas à luz da informação renovada sobre essas próprias práticas.

Nesse nosso contexto social instável e mutante, no qual os meios tradicionais de produção de identidade (família, religião, política, trabalho, etc) se encontram enfraquecidos, é possível imaginar que muitos indivíduos estejam se apropriando do corpo como um meio de expressão do eu (Mattos; Luz, 2009). “O enfraquecimento da consciência coletiva, do espírito de solidariedade e dos valores coletivos tem provocado fragmentação dos laços sociais, levando os sujeitos a supervalorizarem o corpo como o companheiro ideal e fiel" (Mattos; Luz, 2009, p. 493).

Estudos que têm por objeto a obesidade e a busca pelo corpo belo e saudável, na perspectiva das ciências humanas e sociais, tornam-se relevantes na medida em que o corpo magro parece ser o único tipo valorizado e reconhecido na sociedade, gerando sofrimento e adoecimento nos sujeitos que não se enquadram nesses padrões hegemônicos de beleza. "A supervalorização da magreza transforma a gordura em um símbolo de falência moral, e o obeso, mais do que apresentar um peso socialmente inadequado, passa a carregar uma marca moral indesejável, ou seja, um estigma" (Mattos; Luz, 2009, p. 490).

A mídia ajuda a sustentar esse olhar cultural hegemônico ao enfatizar e interferir, por meio de palavras e imagens, na construção dos corpos belos e saudáveis (Mattos; Luz, 2009). A norma atual de magreza ganhou força histórica a partir de meados do século XX, gerando sofrimento nos âmbitos físico, social, afetivo e moral para as pessoas gordas. Entramos no século XXI com a tríade ser bela/jovem/saudável difundida exaustivamente pela mídia. Para Del Priore (2000), a supremacia da aparência em que vivemos coloca a estética como motor da existência. A feiúra é vivida como um drama, e a gordura, como maldição do corpo. A obesidade é o estigma maior dessa maldição. 
Os obesos tornam-se estigmatizados na medida em que não se enquadram nos padrões hegemônicos de beleza da sociedade contemporânea, sendo vítimas de isolamento social, afetivo, e, consequentemente, são acometidos por angústia, depressão e sensação de abandono. Conforme apontado por Vilhena, Novaes e Rocha (2008), a beleza é via para a possibilidade de ascensão social, dos contos de fada (O Príncipe e a Gata Borralheira) às produções cinematográficas (Uma Linda Mulher) e mesmo no mercado de trabalho; beleza é valor e moeda de troca - beleza é capital. Segundo esses autores, a beleza assume lugar como valor social, fazendo com que nossas regulações permanentes, nossos referenciais identitários estejam enraizados nas expectativas relativas ao corpo e qualquer contravenção estética maior provoque um mal-estar.

Partindo do pressuposto de que a mídia parece operar sua ação em todas as esferas da vida social, sintetizando em discursos aspectos de vida ditos ideais, questionamos de que forma ela colabora para esse culto extremo ao corpo belo. Essa inquietação, em realidade, nasceu a partir de resultados de trabalhos anteriores que investigaram, durante um semestre, matérias de saúde publicadas em Veja e Time (Luz, 2010; 2006).

Descobriu-se, na ocasião, que o tema mais abordado por Veja foi o das questões alimentares, responsáveis por 15\% das matérias. Já em Time, o tema mais recorrente foi o das questões mentais e psicológicas, com 25\%, o qual também foi seguido por uma temática relacionada à obtenção de um corpo esbelto (e saudável), representando 16\%. Estes são percentuais que reforçam que, com o avanço da medicina na área estética, a boa aparência se tornou uma necessidade quase tão importante como a saúde e a busca pelo considerado corpo perfeito, dentro dos ditames atuais da moda, uma obsessão para muitas mulheres.

Neste estudo, focamos apenas nessas matérias sobre a busca do corpo belo e saudável publicadas pelas referidas revistas entre janeiro e junho de 2005, as quais 
somam oito em Veja e sete em Time, procurando identificar os padrões de beleza e saúde reforçados pelo discurso midiático e apresentar reflexões sobre o estatuto do corpo na sociedade moderna.

\section{Saúde e beleza no discurso midiático}

Entre as matérias analisadas, chama atenção a publicada por Veja já na primeira edição de 2005, com data de 5 de janeiro. No texto Na balança, sem culpa - NÃO embarcar nas dietas da moda, o autor, o endocrinologista Geraldo Medeiros, afirma que os regimes da moda são uma forma inadequada de lidar com o excesso de peso, acrescentando que:

A última pesquisa pela internet indica que nos últimos trinta anos 1.480 títulos de livros sobre dietas já foram publicados: dieta da lua, do grupo sanguineo, dieta ortomolecular, de South Beach, do Dr. A, B ou C, do homem que bebe, dietas com muito carboidrato ou com pouco carboidrato, dietas que excluem frutas, ou que mandam comer muito alho, alcachofra ou berinjela."

(Medeiros, 2005, p. 67)

No entanto, a matéria Sintonia fina à mesa - depois de contar calorias, carboidratos e proteinas, os cientistas focam no indice glicêmico para melhorar a dieta, publicada na edição de 27 de abril, apresenta uma dieta que pode ser considerada da moda, qual seja: a do índice glicêmico, que define a capacidade de um alimento aumentar os níveis de açúcar no sangue (quanto mais açúcar na corrente sanguínea, maior é a produção do hormônio insulina). O curioso é que uma das fontes dessa matéria é justamente o 
endocrinologista Geraldo Medeiros, que meses antes havia recomendado aos leitores não embarcar nesse tipo de dieta. A do índice glicêmico, em especial, tem algumas artimanhas e é um tanto confusa, conforme informa a matéria, ao trazer exemplos de alimentos calóricos com baixo índice glicêmico e vice-versa.

Reforçando a ideia de modismo, a matéria diz que o regime já caiu no gosto de australianos, canadenses, ingleses e é sucesso nos Estados Unidos. No entanto, para contrabalançar tal incentivo de levar os leitores a embarcarem na dieta da vez, admite que embora o índice seja uma nova e poderosa ferramenta para refinar cardápios e torná-los mais saudáveis, as dietas que se baseiam na quantidade de calorias consumidas diariamente continuam a ser das mais equilibradas, já que se pode comer de tudo, em pequenas quantidades.

Outro tipo de dieta nesses moldes de contar pontos é apresentada na matéria $A$ dieta dos iniciantes - novo livro adapta ao sistema de pontos o regime mais simples que existe: comer pouco e fazer exercícios físicos, publicada na edição de 25 de maio com base no livro A balança dos pontos, do fisiologista Turibio Leite de Barros e da nutricionista Patrícia Bertolucci. O método tem por objetivo ajudar qualquer um a montar um programa para perder quilos extras, casando restrição alimentar e exercícios físicos. A recomendação deles é começar com uma análise minuciosa da alimentação e da atividade física habitual, contabilizando ponto por ponto - com base em duas longas tabelas no fim do livro.

Na onda de divulgar os permitidos e proibidos na busca pelo corpo ideal, ou seja, do que se pode e não se pode comer e como se deve fazê-lo, Veja publica, em 30 de março, a matéria Café-da-manhã emagrece - pois é: um desjejum saudável queima calorias, evita exageros no almoço e... pode ser gostoso, vai sobre os resultados de pesquisa publicada no American Journal of Clinical Nutrition; e, em 4 de maio, a matéria Radicalismo engorda - táticas severas para emagrecer podem ter o efeito contrário em adolescentes, sobre estudo 
da Universidade do Texas, em Austin, que, após acompanhar 500 garotas por quatro anos, concluiu que o uso de laxantes e jejuns prolongados tendem a estimular com os anos mais o ganho do que a perda de peso.

Enquanto Veja parece dar receitas da moda sobre como perder os quilos extras, em Time percebe-se outro foco de abordagem, voltado mais para a saúde do que para a estética. Esse posicionamento pode ser percebido na matéria Tudo bem estar fofinho? Esta é a questão levantada pelo último estudo governamental ${ }^{1}$, publicada em 09 de maio e baseada na polêmica lançada por estudo disponibilizado pelo Centro de Controle e Prevenção de Doenças dos Estados Unidos (CDC), segundo o qual pessoas com sobrepeso, mas não obesas, não teriam maior risco de morrer prematuramente do que pessoas com peso normal.

Numa evidência de que a obesidade e o sobrepeso são problemas sociais, carregados de estigma, a matéria afirma Você pôde quase ouvir o suspiro nacional de alívio que se seguiu nos artigos de jornais, nos programas de rádio, nos monólogos de comediantes tarde à noite (Gorman, 2005, p. 47) 2 .

Ciente da influência de suas matérias na sociedade, a revista Time resolve, um mês mais tarde, lançar uma edição especial, em 06 de junho, intitulada Perca os pneuzinhos! - reportagem especial sobre como entrar em forma mais rápido ${ }^{3}$, com 21 páginas dedicadas ao tema de como tornar os americanos mais saudáveis, a partir do equilíbrio entre comida ingerida e calorias gastas.

O especial, como um todo, ao invés de focar em dietas da moda, enfoca a importância do exercício físico na rotina das pessoas, numa abordagem, novamente, mais voltada à questão da saúde, dos benefícios do exercício, do que propriamente aos padrões estéticos. A matéria Mexa-se - não é apenas uma questão de ser magro. Exercícios fazem coisas extraordinárias para sua saúde. Então, o que você está esperando? ${ }^{4}$ reforça que fazer exercício não é uma questão de magreza, e, sim, de saúde. 
Ainda batendo nessa tecla, a matéria Dos pés à cabeça - os exercícios não deixam você apenas mais bonito, mas também mais forte, tanto mental como fisicamente ${ }^{5}$, apresentada em forma de infográfico, traz os pontos necessários para um programa balanceado de exercícios. Retomando o estudo polêmico do CDC, a matéria Você pode ser gordo e saudável? - se você comer bem e exercitar-se, talvez não importe que você não entre mais nos seus jeans ${ }^{6}$ afirma que não é o número na balança que vai matar você, mas a pressão e o colesterol alto e outros problemas de saúde que surgem com o sedentarismo.

Por fim, o especial termina com a matéria Como envelhecer elegantemente - mantenha seu corpo funcionando no seu melhor, ajustando sua rotina de esportes e exercício à medida que os anos passam ${ }^{7}$, que traz dicas sobre o que as pessoas em processo de envelhecimento devem fazer para se manterem ativas, sem riscos à saúde.

\section{Considerações finais}

Partindo do pressuposto de que a mídia parece operar sua ação em todas as esferas da vida social, sintetizando em discursos aspectos de vida ditos ideais, questionamos, durante a análise das matérias, de que forma ela colabora para o culto ao corpo belo e saudável. No caso de Time, concluímos que a revista parece cultuar mais a busca pelo corpo saudável, ao invés do magro e sarado, abordando o problema da obesidade, do excesso de peso e do sedentarismo motivada por uma polêmica em pauta na sociedade, qual seja o estudo divulgado pelo CDC, sem embarcar em dietas ou exercícios da moda, bem como sem dar um enfoque de mercantilização da saúde e do consumo da beleza em suas páginas. A revista parte da realidade, apoiando-se em práticas sociais presentes na rotina dos norte-americanos, para desempenhar um papel de cunho mais educativo e reflexivo, buscando identificar e trazer alternativas aos problemas do sobrepeso e, principalmente, do sedentarismo, contemplando a questão em suas diferentes faixas etárias. 
Ao reconhecer existir, conforme postulam Adam e Herzlich (2001), uma interpretação coletiva de padrões estéticos socialmente aceitos, qual seja, o do culto à magreza, e ao buscar se ocupar do homem, segundo defende Freyre (2009), como um indivíduo socializado em pessoa, no caso, inserida nos hábitos sedentários da vida norte-americana, a publicação permite empreender uma espécie de reflexividade da vida social, segundo a qual as práticas sociais podem ser examinadas e reformadas à luz da informação renovada sobre essas próprias práticas (Giddens; Pierson, 2000).

Veja, em contrapartida, parece deslizar pelas ondas da moda ao trazer, em suas páginas, pelo menos duas matérias de dietas consideradas $d a v e z$, cultuando, assim, mais a busca pelo corpo magro do que o saudável. Nesse sentido, a revista chega, inclusive, a incorrer em contradição, uma vez que na primeira reportagem sobre os cuidados com o peso, publicada em janeiro, chegou a sugerir aos leitores que não embarcassem em tais dietas. A revista busca, dessa forma, responder aos anseios daqueles que, no nosso contexto social instável e mutante, supervalorizam o corpo como o companheiro ideal e fiel (Mattos; Luz, 2009), buscando torná-lo belo e dentro dos padrões socialmente aceitos.

Assim, considerando que mesmo que não condicione comportamentos ou ações sociais, a mídia atua como um fator de poderosa influência no campo social, construindo, em seu discurso, um recorte da realidade que tem possibilidades de se tornar hegemônico, colaborando na manutenção de práticas e padrões no interior da sociedade. Podemos afirmar, de modo geral, que Veja contribui para a manutenção do estatuto da magreza, enquanto Time tenta modificá-lo, mostrando ser mais importante manter o olho na saúde do que apenas nos ponteiros da balança. 


\section{REFERÊNCIAS}

ADAM, Philippe; HERZLICH, Claudine. Sociologia da doença e da medicina. Bauru: Edusc, 2001.

BERGAMO, Giuliana. Menos gordura, mais neurose. Veja, São Paulo, v. 38, n. 1895, pp. 104-107, 9 mar. 2005.

BUCHALLA, Anna Paula. Sintonia fina à mesa. Veja, São Paulo, v. 38, n. 1902, 27 abr. 2005, p. 118-120.

. Café-da-manhã emagrece. Veja, São Paulo, v. 38, n. 1898, pp. 64-65, 30 mar. 2005.

CIVITA, Victor. Carta do editor. 1968. Disponível em: <http://veja.abril.com.br/numero1/p_020.html>. Acesso em: 10 jun. 2005.

DEL PRIORE, Mary. Corpo a corpo com a mulher: pequena história das transformações do corpo feminino no Brasil. São Paulo: SENAC, 2000.

DELL, Kristina. From head to toe. Time, New York, v. 165, n. 23, pp. 54-55, 6 jun. 2005.

FREYRE, Gilberto. Sociologia da Medicina. São Paulo: É Realizações, 2009.

GIDDENS, Anthony. A transformação da intimidade: sexualidade, amor e erotismo nas sociedades modernas. São Paulo: UNESP, 1994.

. As consequências da modernidade. São Paulo: Unesp, 1991.

GIDDENS, Anthony; PIERSON, Christopher. Conversas com Anthony Giddens: o sentido da modernidade. Rio de Janeiro: Editora FGV, 2000.

GORMAN, Christine. How to age gracefully. Time, New York, v. 165, n. 23, pp. 73-74, 6 jun. 2005.

. Is It O.K. to Be Pudgy? Time, New York, v. 165, n. 19, p. 47, 9 maio 2005.

KLUGER, Jefrey. Couch Potatos, Arise. Time, New York, v. 165, n. 23, pp. 52-53, 6 jun. 2005.

. Can you be fat \& healthy? Time, New York, v. 165, n. 23, pp. 60-63, 6 jun. 2005.

LEMONICK, Michael. Redescovering Playtime. Time, New York, v. 165, n. 23, pp. 56-58, 6 jun. 2005.

LUZ, Lia. A pílula da longevidade à venda nas páginas de Veja. 2006. 123 f. Dissertação (Mestrado em Comunicação Social) - Faculdade de Comunicação Social, PUCRS, Porto Alegre, 2006.

. A pílula da longevidade à venda nas páginas da revista Veja. Intercom - Revista Brasileira de Ciências da Comunicação, São Paulo, v. 33, n. 1, p. 257-276, jan./jun. 2010. Disponível em: <http://200.144.189.84/revistas/ index.php/revistaintercom/article/view/156>. Acesso em: em 12 abr. 2010.

MATTOS, Rafael da Silva; LUZ, Madel Therezinha. Sobrevivendo ao estigma da gordura: um estudo socioantropológico sobre obesidade. Physis, Rio de Janeiro, v. 19, n. 2, pp. 489-507, 2009. Disponível em: $<$ http://www.scielo.br/scielo.php?script=sci_arttext\&pid=S0103-73312009000200014\&lng=en\&nrm=iso $>$. Acesso em: 12 abr. 2010. 
MEDEIROS, Geraldo. Na balança, sem culpa. Veja, São Paulo, v. 38, n. 1886, pp. 66-67, 5 jan. 2005.

MOHERDAUI, Bel. A dieta dos iniciantes. Veja, São Paulo, v. 38, n. 1906, pp. 86-88, 25 maio. 2005.

NEIVA, Paula. Alerta contra a gordura trans. Veja, São Paulo, v. 38, n. 1893, pp. 72-73, 23 fev. 2005.

O ATAQUE DO SANDUBA ASSASSINO. Veja, São Paulo, v. 38, n. 1889, p. 70, 26 jan. 2005.

ORLANDI, Eni. Análise de Discurso: princípios e procedimentos. Campinas: Pontes, 2005.

SCALZO, Marília. Jornalismo de revista. São Paulo: Contexto, 2003.

VEJA. Radicalismo engorda. São Paulo, v. 38, n. 1903, pp. 81-82, 4 maio 2005.

VILHENA, Junia de; NOVAES, Joana de Vilhena; ROCHA, Livia. Comendo, comendo e não se satisfazendo: apenas uma questão cirúrgica? Obesidade mórbida e o culto ao corpo na sociedade contemporânea. Revista Mal-Estar e Subjetividade, v. 8, n. 2, pp. 379-406, jun. 2008.

WALLIS, Claudia. Get moving. Time, New York, v. 165, n. 23, pp. 46-50, 6 jun. 2005.

\section{NOTAS}

1 Tradução do original em inglês "Is it ok to be pudgy? - that's the question raised by the latest government study".

2 Tradução do original em inglês "You could almost hear the national sigh of relief in the newspaper articles, radio, talk shows and monologues of late-night comedians that followed".

3 Tradução do original em inglês "Lose that spare tire! - special report on how to get fitter, faste".

4 Tradução do original em inglês Get moving - it's not just a matter of looking svelte. Exercise does remarkable things for your health. So what are you waiting for?

5 Tradução do original em inglês From head to toe-exercise not only helps you look great; it also makes you stronger, both mentally and physically.

6 Tradução do original em inglês You can be fat $\mathcal{E}$ healthy? - if you eat well and work out, it may not matter if you can't fit into your jeans.

7 Tradução do original em inglês How to age gracefully - keep your body running at its best by adjusting your sports and exercise routines as the years go by. 